\title{
The effect of peanut and grain bar preloads on postmeal satiety, glycemia, and weight loss in healthy individuals: an acute and a chronic randomized intervention trial
}

\author{
Carol S Johnston ${ }^{1,2^{*}}$, Catherine M Trier $^{1}$ and Katie R Fleming ${ }^{1}$
}

\begin{abstract}
Background: Peanut consumption favorably influences satiety. This study examined the acute effect of peanut versus grain bar preloads on postmeal satiety and glycemia in healthy adults and the long-term effect of these meal preloads on body mass in healthy overweight adults.

Methods: In the acute crossover trial $\left(n=15 ; 28.4 \pm 2.9 y ; 23.1 \pm 0.9 \mathrm{~kg} / \mathrm{m}^{2}\right)$, the preload (isoenergetic peanut or grain bar with water, or water alone) was followed after 60 min with ingestion of a standardized glycemic test meal. Satiety and blood glucose were assessed immediately prior to the preload and to the test meal, and for two hours postmeal at 30-min intervals. In the parallel-arm, randomized trial $\left(n=44 ; 40.5 \pm 1.6 y, 31.8 \pm 0.9 \mathrm{~kg} / \mathrm{m}^{2}\right)$, the peanut or grain bar preload was consumed one hour prior to the evening meal for eight weeks. Body mass was measured at 2-week intervals, and secondary endpoints included blood hemoglobin A1c and energy intake as assessed by $3-d$ diet records collected at pre-trial and trial weeks 1 and 8 .
\end{abstract}

Results: Satiety was elevated in the postprandial period following grain bar ingestion in comparison to peanut or water ingestion ( $p=0.001$, repeated-measures ANOVA). Blood glucose was elevated one hour after ingestion of the grain bar as compared to the peanut or water treatments; yet, total glycemia did not vary between treatments in the two hour postprandial period. In the 8-week trial, body mass was reduced for the grain bar versus peanut groups after eight weeks ( $-1.3 \pm 0.4 \mathrm{~kg}$ versus $-0.2 \pm 0.3 \mathrm{~kg}, \mathrm{p}=0.033$, analysis of covariance). Energy intake was reduced by $458 \mathrm{kcal} / \mathrm{d}$ in the first week of the trial for the grain bar group as compared to the peanut group $(p=0.118)$. Hemoglobin A1c changed significantly between groups during the trial $(-0.25 \pm 0.07 \%$ and $-0.18 \pm 0.12 \%$ for the grain bar and peanut groups respectively, $\mathrm{p}=0.001$ ).

Conclusions: Compared to an isoenergetic peanut preload, consumption of a grain bar preload one hour prior to a standardized meal significantly raised postmeal satiety. Moreover, consumption of the grain bar prior to the evening meal was associated with significant weight loss over time suggesting that glycemic carbohydrate ingestion prior to meals may be a weight management strategy.

Keywords: Meal preload, Peanut, Grain bar, Glycemia, Satiety, Weight loss

\footnotetext{
* Correspondence: carol.johnston@asu.edu

${ }^{1}$ School of Nutrition and Health Promotion, Arizona State University, Phoenix, AZ 85004, USA

${ }^{2} 500$ North 3rd Street, Phoenix, AZ 85004, USA
} 


\section{Background}

Between 1980 and 2004, obesity prevalence doubled in the U.S., and the most recent statistics show that $28 \%$ of Americans are obese, up from 23\% in 2004 [1]. For adults 20 years and older, the prevalence is higher at 34\% [2]. Although much time and effort has been directed at developing weight loss diets or exercise programs that promote successful weight loss, these attempts have been largely unsuccessful, in part because individuals are not willing to make (and sustain) major dietary and/or lifestyle changes. This futileness is evident in the U.S. Department of Health and Human Service's 2010 and 2020 Healthy People targets for reducing adult obesity prevalence in the U.S., $15 \%$ and $30.6 \%$ respectively. New approaches for combating obesity are needed. Identifying simple, unintimidating diet strategies to help individuals control hunger may be a useful approach to weight management.

Early survey data showed that Americans who consumed five or more servings of peanuts and/or tree nuts per week were thinner than those who consumed these products less often $[3,4]$. These foods are micronutrient dense and high protein, characteristics that influence satiety and energetics [5-7]. Peanuts and tree nuts also reduce meal-induced glycemia, a characteristic that may contribute to their satiating effects since postprandial glycemia has been related to both satiety and reduced energy intake at subsequent meals [8,9]. In acute feeding trials, peanut butter and almond ingestion at mealtime reduced postprandial glycemia 40-50\% [10-12]. Several extended feeding trials examined the effect of tree nut consumption on weight gain [13-15]. In these trials, participants who incorporated 2-3 servings of peanuts or tree nuts into their diets daily (340-500 kcal) compensated for a majority of these calories by displacement of other food items in the diet, and did not gain weight. Hence, it appears that the high satiety value of peanuts and tree nuts effectively regulates daily calorie intake.

Although there is general consensus that peanut and tree nut ingestion have measurable effects on energetics, these trials do not explain the survey data that related body thinness to peanut and nut consumption. In these surveys, the quantity of peanuts/nuts consumed by individuals was much less than that used in the experimental trials, less than one serving per day versus $2-3$ servings per day. To date, a randomized clinical trial has not been conducted to explore the impact of modest peanut consumption $(170 \mathrm{kcal}$ or $28 \mathrm{~g}$, an amount equivalent to one serving per day) on body weight. It is possible that a single serving of peanuts or tree nuts daily would have a satiating effect with fewer calories, a combination that may promote modest weight loss over time.

This study examined the acute effect of peanut ingestion (23 g) on postmeal satiety in healthy adults, and the longterm satiating effect of daily peanut ingestion $(28 \mathrm{~g} / \mathrm{d})$ on body mass over an 8-week period in overweight adults. For both trials, the peanuts were ingested as a preload one hour prior to mealtime to capitalize on their purported satiating effects. Others have demonstrated that a protein preload at 30,120 , or 180 minutes prior to a meal was not associated with reductions in total energy intake (e.g., energy of preload + meal) whereas a protein preload administered at 1 hour prior to a meal reduced total energy intake by as much as $134 \mathrm{kcal}$ [16-18]. A prepackaged, carbohydraterich, grain-based snack bar (140 kcals) was selected as the control treatment as it was shown to have neutral effects on body weight in a long-term feeding trial [15].

\section{Methods}

Healthy, non-smoking adults aged 20-65 y who were not diabetic by self-report and who did not have known peanut or tree nut allergies were recruited for these trials from a campus community. Eligible volunteers did not report a recent history of dieting and/or change in body weight $( \pm 5 \mathrm{~kg})$, prescription drug use that impacted eating behavior or body weight, more than three highintensity exercise sessions per week, or unresolved medical conditions and disease. Sixty-four overweight or obese volunteers (body mass index [BMI] $>25 \mathrm{~kg} / \mathrm{m}^{2}$ ) entered the 8-week trial, and a separate pool of volunteers $\left(\mathrm{n}=15\right.$; BMI, $18-30 \mathrm{~kg} / \mathrm{m}^{2}$ ) entered the acute trial. Written informed consent was obtained from all participants, and the study was approved by the Institutional Review Board at Arizona State University.

\section{Acute trial}

Participants consumed a standard dinner meal (sub sandwich, soda, and cookie) the night before testing and fasted overnight (no food or beverage with the exception of water for $>10 \mathrm{~h}$ ). At the test site, fasting participants were assigned to one of three treatments using a randomized block design: ingestion of $23 \mathrm{~g}(0.82 \mathrm{oz} ; 140 \mathrm{kcal})$ peanuts with $1 \mathrm{c}$ water followed after 60 minutes with ingestion of a buttered bagel and juice; ingestion of one grain bar (140 kcal) with $1 \mathrm{c}$ water followed after 60 minutes with ingestion of a buttered bagel and juice; or, ingestion of $1 \mathrm{c}$ water followed after 60 minutes with ingestion of a buttered bagel and juice. The standardized test meal was composed of commercially purchased foods (bagel, 114 g; berry juice, $200 \mathrm{~g}$; and margarine, $14 \mathrm{~g})$ and contained $460 \mathrm{kcal}(68 \%$ carbohydrate, $23 \%$ fat, $9 \%$ protein).

Blood was collected immediately before peanut/grain bar/water ingestion, immediately before bagel ingestion, and at 30-minute intervals for the 2 -h period after ingestion of the bagel meal. Perceived satiety was assessed at these same intervals during the trial using a validated Likert scale [19]. Blood was analyzed for glucose at each time point and for insulin at three time points: prepeanut/grain bar ingestion, pre-meal ingestion, and 
30 minutes postmeal ingestion. The entire trial lasted three weeks, and each participant reported to the test site weekly and followed the same protocol to complete all treatments. Each week, all treatments were examined with one-third of participants receiving the same treatment. During the 3-week trial period, participants were asked to maintain their normal activities but to record all food and beverage consumption on the three treatment days.

\section{Long-term trial}

The 8-week trial employed a parallel arm design. Participants were paired by age, gender, and BMI, and paired individuals were randomly assigned to the treatment groups: peanut or grain bar. To encourage a standard diet plan across groups, all participants received foodbased, low-fat diet counseling as outlined in the U.S. Dietary Guidelines and using the participant's calculated basal metabolic rate. All participants received the same instructions for consuming the test food 60 minutes prior to the dinner meal daily during the trial. Participants met with study investigators at baseline and at weeks 2, 4, 6, and 8 for anthropometric assessment and food pick-up. On the three days immediately preceding the start of the trial, the first three days of the trial, and at trial week 8 , participants were asked to complete 3 -d diet records. At the end of the 8-week trial, participants were encouraged to continue the feeding protocol and return for follow-up testing at 12 and 16 weeks. A fasting blood sample was collected at baseline, week 8, and week 16 and analyzed for glucose, hemoglobin A1c, and insulin. Participants were asked to record discretionary physical activities daily during the trial (type and duration) and to bring this recorded log to the test site biweekly along with the written diet records. The physical activities were assigned an energy value to estimate daily discretional energy expenditure.

\section{Test foods}

The test foods, individual packets of peanuts $(1 \mathrm{oz})$ and grain bars $(1.4 \mathrm{oz})$, were purchased from commercial outlets and shelf-stable; one prepackaged item equaled the preload serving size in the long-term trial eliminating the need for participants to measure the preload portion. Test foods were supplied to participants at two week intervals during the 8-week trial. Participants were also offered their respective test foods during the follow-up period, weeks 8 through 16 . The test food daily dosages for the long-term trial were $28 \mathrm{~g}$ peanuts (Kraft Foods, East Hanover, NJ: $170 \mathrm{kcal}, 5 \mathrm{~g}$ total carbohydrate, $15 \mathrm{~g}$ total fat, $2 \mathrm{~g}$ saturated fat, $7 \mathrm{~g}$ protein, $115 \mathrm{mg}$ sodium, and $2 \mathrm{~g}$ fiber) and $40 \mathrm{~g}$ grain bar (Target Brands, Inc, Minneapolis, MN: 140 kcals, 25 g total carbohydrate, 3 g total fat, $0 \mathrm{~g}$ saturated fat, $2 \mathrm{~g}$ protein, $130 \mathrm{mg}$ sodium, and $2 \mathrm{~g}$ fiber). Identical foods were used as the preloads in the acute trial; however, the peanut dosage was reduced to $23 \mathrm{~g}$ to keep isoenergetic with the grain bar and eliminate energy as a confounding factor between preloads.

\section{Measures and chemical analyses}

Body composition measures (weight in light clothing and body fat percentage) were collected at baseline for both trials (bioelectrical impedance methods; Tanita scale, Model TBF-300A, Tanita Corp, Arlington Heights, IL). In the long-term trial, body composition measures were also collected at trial weeks $2,4,6$, and 8 , as well as at weeks 12 and 16 of the follow-up period. Waist circumference was measured at the umbilicus using a flexible tension tape. In the acute trial, capillary glucose was measured using a calibrated OneTouch glucometer (LifeScan Inc., Milipitas, CA); serum insulin concentrations were assessed by radioimmunoassay (Millipore, St. Charles, MO). For the longterm trial, fasting blood samples were analyzed for serum glucose using a COBAS C111 chemistry analyzer (Roche Diagonstics, Indianapolis, IN) and hemoglobin A1c using an autoanalyzer (DCA200+, Siemens Healthcare Diagnostics Inc. Deerfield, IL). Serum insulin concentrations were assessed as outlined for the acute trial.

\section{Statistical analyses}

Results are expressed as means $\pm \mathrm{SE}$, and all data analyses were conducted using PASW Statistics 19.0, (Predictive Analytics SoftWare Statistics package, IBM, 2009). $P$ values $\leq 0.05$ were considered significant. Based on our previous work [20] a sample size of 15 in the acute trial provided an $88 \%$ power to observe a $16 \%$ change in postprandial glycemia. In the acute trial, total satiety for the postprandial period (0-120 min) was calculated as the area-under-the-curve (AUC) using the trapezoidal rule. Postprandial glycemia (0-120 min) was calculated as the incremental AUC (iAUC). Satiety and glycemia data were normally distributed; insulinemia data were normally distributed following removal of one outlier ( $>3$ SD from mean). Treatment effects were assessed using the repeated-measures ANOVA test, and the LSD posthoc test was used to identify differences between individual means.

For the long-term trial analyses, between groups analysis of covariance (ANCOVA) was used with baseline values as the covariate. Independent t-test was used to assess differences at baseline. Fasting glucose and insulin were not normally distributed, and the nonparametric Mann-Whitney test was used to evaluate change over time between groups. Body mass data at week 8 were assessed for completers only and by using the intentionto-treat, Last Observation Carried Forward (LOCF), method to impute missing values. 


\section{Results}

\section{Acute trial}

Two men and thirteen women $(28.4 \pm 2.9$ y; BMI, $23.1 \pm$ $0.9 \mathrm{~kg} / \mathrm{m}^{2}$ ) completed the acute trial. Serum glucose and insulin concentrations for all participants (calculated from fasting blood samples collected on test days) fell below cutoffs for prediabetes (glucose $<5.55 \mathrm{mmol} / \mathrm{L}$ ) and insulin resistance (serum insulin $<18 \mu \mathrm{U} / \mathrm{mL}$ ) (Table 1). Both peanut and grain bar consumption were associated with greater satiety than the control treatment after one hour $(\mathrm{p}<0.05)$ (Figure 1). Grain bar consumption was associated with greater satiety versus peanut and control at 60 and $90 \mathrm{~min}$ postmeal ingestion ( $\mathrm{p}<0.040)$. At $120 \mathrm{~min}$, grain bar consumption remained more satiating than peanut consumption $(p=0.023)$. The $0-120$ min AUC for satiety was significantly greater for the grain bar treatment versus the peanut and control treatments $(\mathrm{p}<0.006)$ (see inset, Figure 1). Total energy intakes were 100-120 kcal less on days the peanuts and bars were ingested as compared to the control treatment, but these values did not differ significantly by treatment $(1771 \pm 149 \mathrm{kcal}, 1756 \pm 144 \mathrm{kcal}$; and $1878 \pm 209 \mathrm{kcal}$ respectively; $\mathrm{p}=0.709$ ).

Mean fasting blood glucose concentrations did not differ by treatment (range: $4.9 \pm 0.1 \mathrm{mmol} / \mathrm{L}$ to $5.0 \pm 0.1 \mathrm{mmol} / \mathrm{L}$ ); however, blood glucose was significantly elevated one hour after ingestion of the grain bar $(+0.8 \pm 0.1 \mathrm{mmol} / \mathrm{L})$ versus that recorded for the peanut or control treatments $(-0.1 \pm$ $0.1 \mathrm{mmol} / \mathrm{L}$ and $-0.1 \pm 0.1 \mathrm{mmol} / \mathrm{L}$, respectively) $(\mathrm{p}<0.001$; Figure 2). At 30 min postmeal, mean blood glucose for the control treatment was significantly greater than that for peanut or grain bar $(\mathrm{p}<0.050)$. Thereafter, no further differences in plasma glucose were noted between groups. For the 0-120 min postprandial period, iAUC for blood glucose did not vary between treatments (see inset, Figure 2).

The mean fasting serum insulin concentrations did not differ by treatment (range: $3.8 \pm 0.7 \mu \mathrm{U} / \mathrm{mL}$ to $4.1 \pm$ $0.8 \mu \mathrm{U} / \mathrm{mL}$ ), and the change in serum insulin during the trial period did not differ by group $(\mathrm{p}=0.161$, repeated measures ANOVA; Figure 3). The changes in serum insulin one hour following the preloads were $8.9 \pm 1.4 \mu \mathrm{U} /$ $\mathrm{mL}, 2.0 \pm 0.5 \mu \mathrm{U} / \mathrm{mL}$ and $-0.6 \pm 0.4 \mu \mathrm{U} / \mathrm{mL}$ for the grain bar, peanut, and control treatments respectively. The

Table 1 Baseline characteristics of participants in acute glycemia trial $(\mathbf{n}=15)^{1}$

\begin{tabular}{lcc}
\hline Gender, M/F & $2 / 13$ \\
Age, y & $28.4 \pm 2.9$ & $(20-58)$ \\
Weight, $\mathrm{kg}$ & $66.4 \pm 3.6$ & $(54-106)$ \\
Body mass index, $\mathrm{kg} / \mathrm{m}^{2}$ & $23.1 \pm 0.9$ & $(18-31)$ \\
Serum fasting glucose, $\mathrm{mmol} / \mathrm{L}$ & $4.9 \pm 0.1$ & $(4.3-5.3)$ \\
Serum fasting insulin, $\mathrm{MU} / \mathrm{mL}$ & $4.2 \pm 0.7$ & $(2-10)$ \\
\hline
\end{tabular}

${ }^{1}$ Data represent mean $\pm \mathrm{SE}$; range in parentheses. Glucose and insulin concentrations were averaged from 3 fasting samples and not correlated to age, weight, or body mass index. incremental rise in serum insulin at 30 min following ingestion of the bagel and juice meal did not differ among treatments (range: $32-39 \mu \mathrm{U} / \mathrm{mL}$ ).

\section{Long-term trial}

Of the 64 individuals enrolled in the trial, four did not start the trial and ten dropped out during the first two weeks of the trial. There were no significant differences by gender, age, weight, BMI, or body fat percentage between participants who remained in the trial at week 2 and those who did not. An additional six individuals did not keep all appointments for the biweekly visits through week 8. Personal reasons were cited as the cause of this attrition. Data are presented for the 44 participants who completed the 8-week trial $(n=23$ [9 males], peanut group; $\mathrm{n}=21$ [7 males], grain bar group) (Table 2). Food record analyses (i.e., the fraction of records that listed the test food) suggested that compliance rates for the food interventions were $94 \%$ and $67 \%$ at week $1(\mathrm{p}=0.092)$ and $82 \%$ and $74 \%$ at week $8(\mathrm{p}=0.823)$ for the peanut and grain bar groups respectively. Estimated energy expenditure for discretionary physical activity did not differ between groups during week 1 of the study $(138 \pm 19 \mathrm{kcal} / \mathrm{d}$ and $116 \pm 19 \mathrm{kcal} / \mathrm{d}$ for peanut and bar groups respectively), and energy expenditure did not change between groups during the study $(131 \pm 29 \mathrm{kcal} / \mathrm{d}$ and $112 \pm 17$ $\mathrm{kcal} / \mathrm{d}$ respectively at week $8 ; \mathrm{p}=0.898$ for interaction).

Mean values for body weight, body fat percentage, and waist circumference decreased for participants at the end of the 8-week trial. Gender, but not age, was related to weight loss; hence, gender was entered as a covariate in all analyses. The decrease in body weight was significantly greater for the grain bar participants versus the peanut participants $(-1.3 \pm 0.4 \mathrm{~kg}$ [range: -5.3 to $+1.8 \mathrm{~kg}$ ] and $-0.2 \pm 0.3 \mathrm{~kg}$ [range: -3.8 to $+2.5 \mathrm{~kg}$ ] respectively; $\mathrm{p}=0.033$ ) (Table 2). Using the intention-to-treat LOCF method to impute missing values at week 8 , the significance between groups for weight loss was strengthened $(\mathrm{p}=0.008)$. However, after the 8-week follow-up period, the change in body weight between groups was no longer significant (Figure 4). At the end of the 8-week follow-up period, a statistical trend for change in body fat percentage between groups was evident with a greater reduction in body fat noted for the grain bar group as compared to the peanut group $(-1.6 \pm 0.5 \%$ and $-0.5 \pm 0.3 \%$ respectively, $\mathrm{p}=0.089$ ) (Table 2 ). Waist circumferences did not vary significantly between groups during the trial (Table 2).

The mean energy intake for the three days immediately prior to the start of the trial did not differ by group $(1706 \pm 112 \mathrm{kcal} / \mathrm{d}$ and $1715 \pm 134 \mathrm{kcal} / \mathrm{d}$, peanut and grain bar groups respectively) (Table 3 ). During the first 3 days of the trial, the mean daily energy intake in the grain bar group fell $359 \pm 177 \mathrm{kcal} / \mathrm{d}$ relative to baseline 


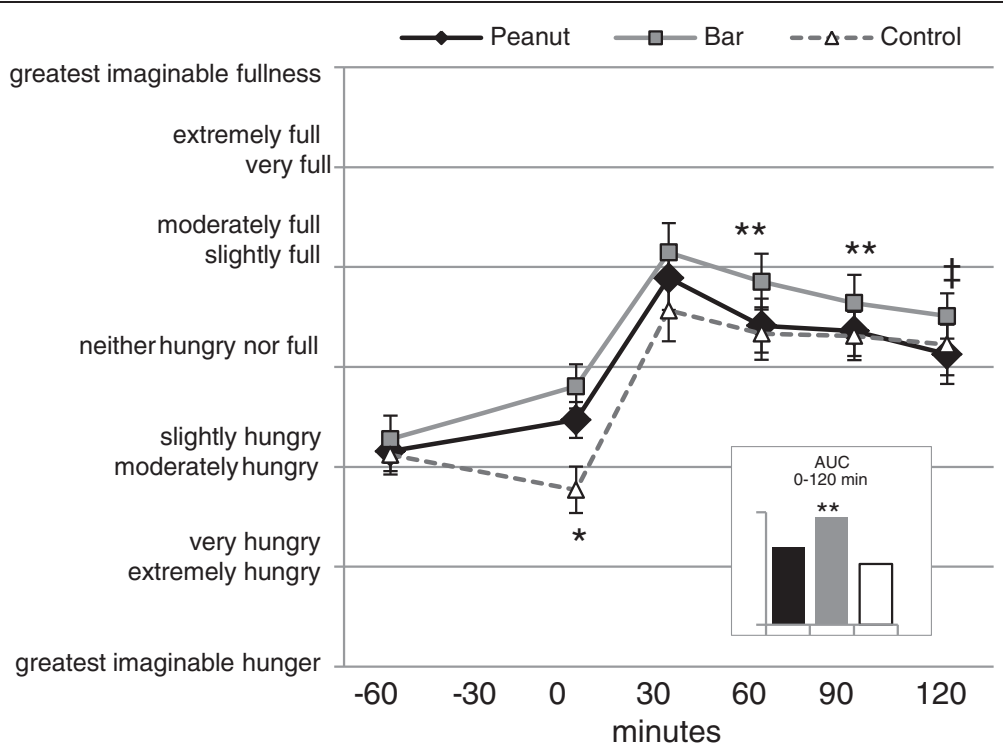

Figure 1 Perceived satiety during the acute trial (mean $\pm S E ; n=15$ ). At time 0 the test meal was consumed, which was exactly one hour after ingestion of the control treatment (1 c water) or the peanut or grain bar treatments, each with 1 c water. Satiety curves differed significantly (repeated measures ANOVA, time $\times$ group interaction; $p=0.002$ ). The area-under-curve for $0-120$ minutes differed by treatment (see inset; $p=0.003$ ). * satiety for control treatment significantly less than that for peanut or grain bar $(p<0.05) .{ }^{* *}$ satiety for grain bar significantly greater than that for peanut or grain bar $(p<0.05)$. ₹ satiety for grain bar significantly greater than that for peanut $(p=0.023)$.

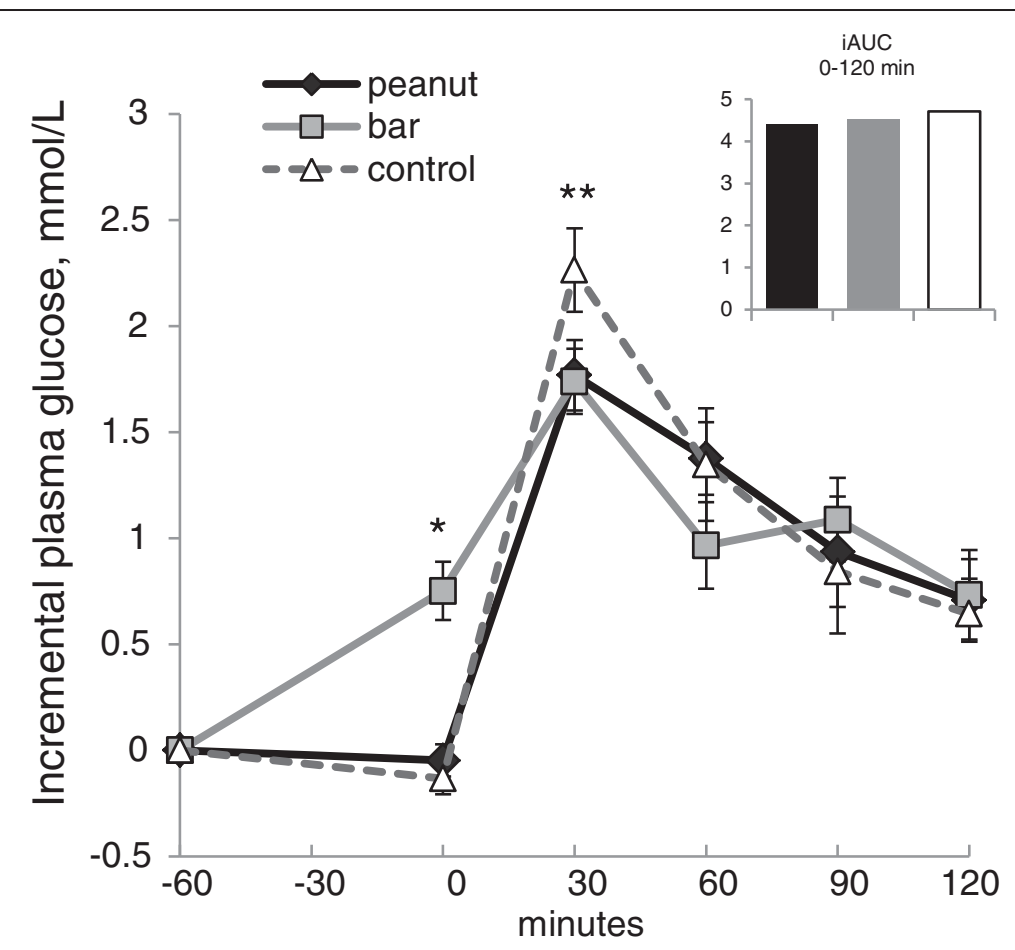

Figure 2 Incremental serum glucose for the acute trial (mean $\pm S E ; \mathbf{n = 1 5}$ ). At time 0 the test meal was consumed, which was exactly one hour after ingestion of the control treatment (1 c water) or the peanut or grain bar treatment, each with $1 \mathrm{c}$ water. Incremental plasma glucose curves differed significantly (repeated measures ANOVA, time $x$ group interaction; $p=0.023$ ). The incremental area-under-curve for $0-120$ minutes did not differ by treatment (see inset; $p=0.901)$. ${ }^{*}$ glucose excursion for grain bar significantly greater than that for peanut or control $(p<0.001)$. ** glucose excursion for control significantly greater than that for peanut or grain bar $(p<0.05)$. 


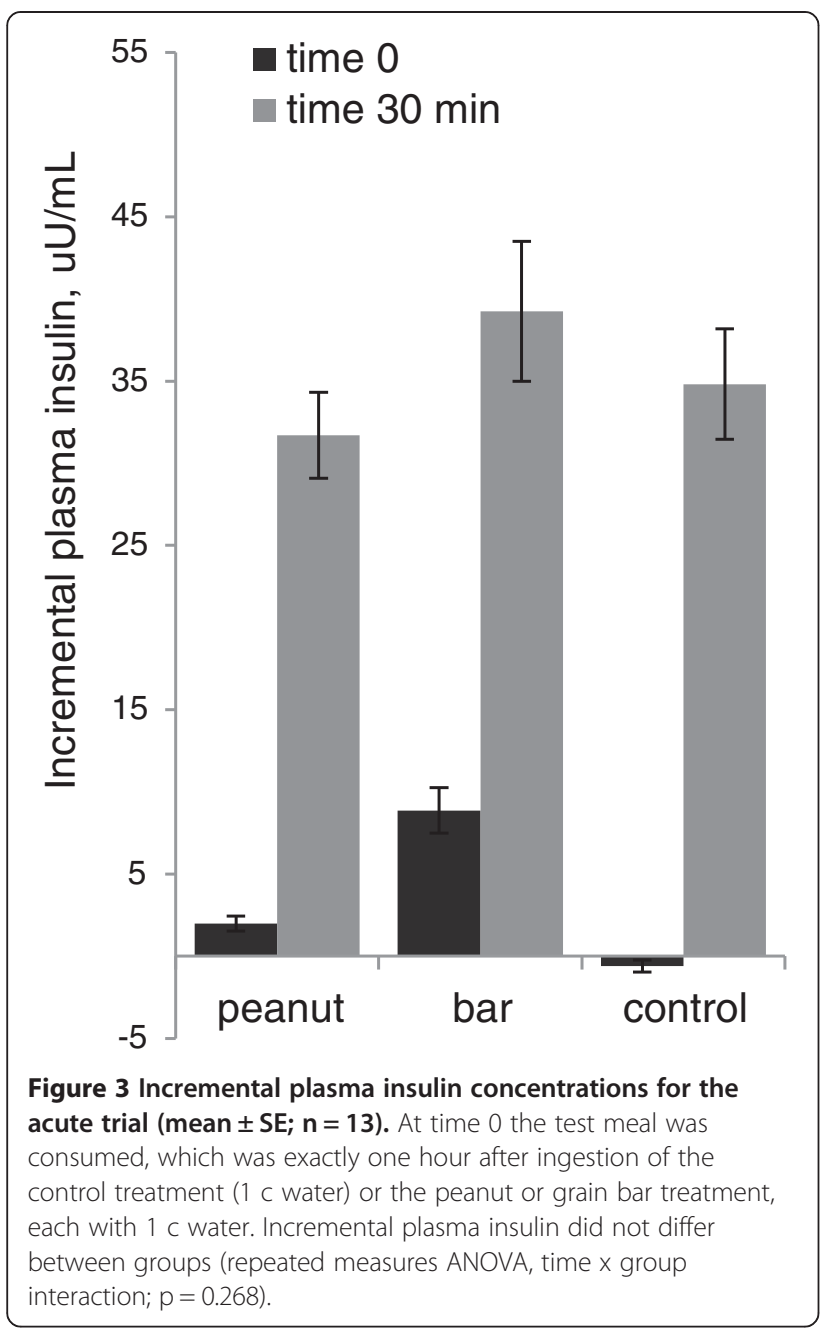

whereas the mean energy intake rose $99 \pm 201 \mathrm{kcal} / \mathrm{d}$ in the peanut group ( $\mathrm{p}=0.118$ for interaction; Table 3$)$. At week 8 , mean daily energy intakes for both groups were within $80 \mathrm{kcal}$ of the baseline value. Protein and fiber intakes $(\mathrm{g} / \mathrm{d})$ tended to increase in the peanut group in the first week of the trial as compared to intakes in the grain bar group $(0.05<\mathrm{p}<0.10$; Table 3$)$.

Hemoglobin A1c was reduced $0.25 \pm 0.07 \%$ in the grain bar group versus a reduction of $0.18 \pm 0.12 \%$ in the peanut group $(\mathrm{p}=0.001$; Table 2$)$. This significance between groups was retained after controlling for the change in body weight over the same period $(\mathrm{p}=0.006)$; however, follow-up data collected eight weeks after the trial ended indicated that the change from baseline for hemoglobin A1c was no longer different between groups (Table 2).

\section{Discussion}

Cross-sectional studies have associated numerous health benefits with regular nut consumption [7,21], and the literature describing the inverse association between nut consumption and body weight is robust [22-24]. Theo- retical explanations for this association include enhanced satiety and caloric compensation, a strong thermic response following ingestion, and incomplete digestion with enhanced fecal fat losses $[5,7,25]$. Yet, randomized intervention trials that have examined the impact of daily nut consumption on body weight demonstrated only neutral effects [13-15,26-29], possibly a consequence of the high caloric value of the nut allotments (240-1374 kcal). In the present report, the nut dosage was modest (1 serving or $170 \mathrm{kcal}$ ) and consumed as a preload 1-hour prior to mealtime to maximize purported satiety potential; however, daily nut ingestion did not impact body weight over time.

The favorable effects of grain bar ingestion, the control treatment, in both the acute and long-term trials were unexpected as others have used this control treatment with neutral effects [15]. Furthermore, preloads composed of glycemic carbohydrate increased energy consumption at mealtime in several studies $[17,30]$. In the acute trial, in comparison to the peanut and/or water treatments, grain bar consumption one hour prior to the test meal was associated with greater perceived satiety at 60,90 , and 120 minutes postmeal and with greater blood glucose concentrations at the time the test meal was consumed. Thus, grain bar ingestion was associated with a strong, sustained satiety response that was not observed for peanut ingestion. The observed increase in perceived satiety noted with the consumption of a food item that displays a relatively high-glycemic-response contradicts a body of literature demonstrating that postprandial glycemia is directly associated with appetite $[8,9,31,32]$.

Anderson and colleagues [33] proposed an explanation for these seemingly contradictory responses by suggesting that high glycemic carbohydrates promote satiety in the short-term (one hour after ingestion) whereas low glycemic carbohydrates are associated with a delayed satiety ( 2 to 3 hours post-ingestion) consistent with their delayed impact on blood glucose concentrations. Indeed, controlled trials demonstrate increased fullness [34] and lower mealtime energy intakes [35] one hour after the ingestion of high glycemic preloads versus low glycemic preloads and three hours after the ingestion of a fiberrich carbohydrate preload versus an isocaloric bread preload [36]. Furthermore, the glucostatic theory, proposed by Mayer in 1952 [37], suggested that food intake is regulated by glucoreceptors in the hypothalamus that sense glucose utilization and adjust food intake to maintain metabolic glucose at a steady-state. Accordingly, satiety is maximized when blood glucose concentrations are high. Hence, the timing of the preloads in the present report (one hour prior to a meal) likely contributed to the strong satiating effects of the grain bar 1.5 hours later.

Interestingly, although both glucose and insulin concentrations were significantly elevated 1-hour following the ingestion of the grain bar as compared to peanut or 
Table 2 Change from baseline in participant characteristics at the end of the 8-week trial and at follow-up at week 16 by treatment group ${ }^{1}$

\begin{tabular}{|c|c|c|c|c|c|c|}
\hline & $\mathrm{n}^{2}$ wk8/wk16 & Baseline & Week 8 & $p$ & Week 16 & $p$ \\
\hline \multicolumn{7}{|c|}{ Body weight, $\mathrm{kg}^{*}$} \\
\hline Peanut & $23 / 23$ & $87.0 \pm 3.9$ & $-0.2 \pm 0.3$ & 0.033 & $0.2 \pm 0.5$ & 0.196 \\
\hline Grain bar & $21 / 19$ & $82.5 \pm 3.7$ & $-1.3 \pm 0.4$ & & $-1.0 \pm 0.6$ & \\
\hline \multicolumn{7}{|l|}{ Body fat, \%* } \\
\hline Peanut & $23 / 23$ & $40.0 \pm 1.7$ & $-0.4 \pm 0.3$ & 0.429 & $-0.5 \pm 0.3$ & 0.089 \\
\hline Grain bar & $21 / 19$ & $40.6 \pm 1.3$ & $-0.7 \pm 0.4$ & & $-1.6 \pm 0.5$ & \\
\hline \multicolumn{7}{|c|}{ Waist circumference, $\mathrm{cm}^{*}$} \\
\hline Peanut & $22 / 20$ & $104.6 \pm 2.9$ & $-4.1 \pm 1.1$ & 0.254 & $-5.9 \pm 1.6$ & 0.495 \\
\hline Grain bar & $21 / 18$ & $99.5 \pm 2.2$ & $-1.5 \pm 1.0$ & & $-4.4 \pm 1.2$ & \\
\hline \multicolumn{7}{|c|}{ Serum fasting glucose, $\mathrm{mmol} / \mathrm{L}$} \\
\hline Peanut & $23 / 21$ & $5.5 \pm 0.4 \dagger$ & $-0.4 \pm 0.3$ & 0.254 & $-0.4 \pm 0.3$ & 0.554 \\
\hline Grain bar & $21 / 18$ & $5.0 \pm 0.5$ & $-0.1 \pm 0.1$ & & $-0.02 \pm 0.12$ & \\
\hline \multicolumn{7}{|c|}{ Hemoglobin A1c, \%* } \\
\hline Peanut & $22 / 20$ & $5.67 \pm 0.27$ & $-0.18 \pm 0.12$ & 0.001 & $-0.16 \pm 0.15$ & 0.159 \\
\hline Grain bar & $21 / 18$ & $5.35 \pm 0.10$ & $-0.25 \pm 0.07$ & & $-0.07 \pm 0.06$ & \\
\hline \multicolumn{7}{|c|}{ Serum fasting insulin, uM } \\
\hline Peanut & $23 / 21$ & $22.5 \pm 2.7$ & $-1.5 \pm 2.5$ & 0.226 & $9.9 \pm 13.3$ & 0.632 \\
\hline Grain bar & $21 / 18$ & $20.8 \pm 4.5$ & $-6.5 \pm 3.9$ & & $-7.1 \pm 4.8$ & \\
\hline
\end{tabular}

${ }^{1}$ Data represent mean \pm SE. P values for ANCOVA with baseline value as covariate; data not normally distributed (glucose and insulin) assessed for change by treatment using non-parametric Mann-Whitney test. *Indicates significant time effect at week 8 (repeated measures ANOVA). +Indicates significant difference at baseline between groups. ${ }^{2}$ Data shown for participants completing the 8 -week trial ( $n=23$ and 21 for peanut and grain bar groups respectively). Reduced sample sizes indicate attrition at follow-up and/or missing data point.

water ingestion, the incremental area-under-curve for glucose during the postprandial period $(0-120 \mathrm{~min}$ postmeal) did not differ significantly between treatments. However, it is likely that these results do not accurately portray the magnitude of total glycemia following grain

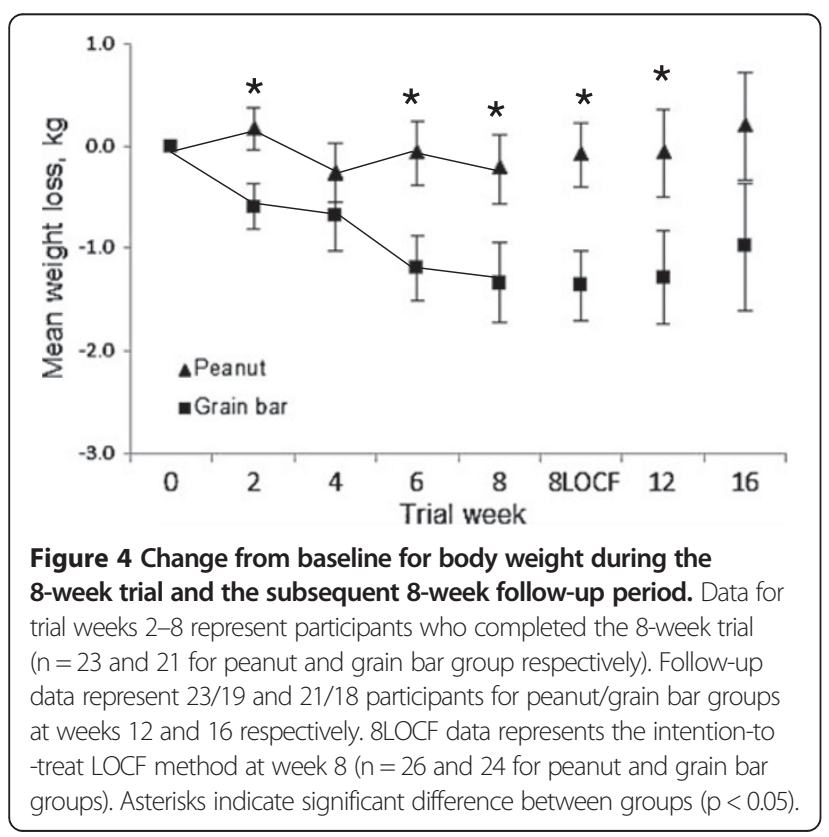

bar ingestion since blood samples were not collected at the 30-minute interval after preload ingestion. Regardless, grain bar ingestion had an immediate, glycemic and insulinemic response that was not sustained once the test meal was ingested.

The rise in both blood glucose and insulin one hour after grain bar ingestion coincided with the test meal ingestion and may have contributed to the attenuation of the postprandial glycemic response and to the rise in satiety ratings. Following nut ingestion a rise in insulin but not glucose concentrations was observed at 60 minutes, and although postprandial glycemia at 30 min was similar to the grain bar treatment, perceived satiety was not impacted throughout the postprandial period relative to control. The insulintropic action of dietary protein is well documented and believed to relate to bioactive peptides or specific amino acids [38-40]. The rise in insulin following peanut ingestion may have abetted the reduction in postmeal glycemia, but the absence of a glycemic response prior to the ingestion of the test meal may be linked to the low satiety ratings observed for peanut ingestion.

Glucagon-like peptide (GLP)-1, an incretin hormone released from mucosal cells in response to nutritive and non-nutritive agents, contributes to the suppression of appetite during the postprandial period by direct central 
Table 3 Change from baseline in 24-h intakes at trial week 1 and trial week 8 by treatment group ${ }^{1,2}$

\begin{tabular}{|c|c|c|c|c|c|c|}
\hline & $n^{3}$ wk1/wk8 & Baseline & Change at week 1 & $P$ & Change at week 8 & $P$ \\
\hline \multicolumn{7}{|c|}{ Energy intake, kcal } \\
\hline Peanut & $15 / 15$ & $1706 \pm 112$ & $99 \pm 201$ & 0.118 & $77 \pm 161$ & 0.409 \\
\hline Grain bar & $13 / 19$ & $1715 \pm 134$ & $-359 \pm 177$ & & $-69 \pm 139$ & \\
\hline \multicolumn{7}{|c|}{ Protein intake, $\mathrm{g}$} \\
\hline Peanut & $15 / 15$ & $67 \pm 4$ & $9 \pm 8$ & 0.070 & $7 \pm 6$ & 0.218 \\
\hline Grain bar & $13 / 19$ & $67 \pm 6$ & $-7 \pm 8$ & & $-1 \pm 5$ & \\
\hline \multicolumn{7}{|c|}{ Carbohydrate intake, g } \\
\hline Peanut & $15 / 15$ & $230 \pm 18$ & $-0.3 \pm 18.4$ & 0.144 & $-17 \pm 18$ & 0.605 \\
\hline Grain bar & $13 / 19$ & $223 \pm 18$ & $-49 \pm 23$ & & $-22 \pm 14$ & \\
\hline \multicolumn{7}{|l|}{ Fat intake, $g$} \\
\hline Peanut & $15 / 15$ & $57 \pm 5$ & $7 \pm 9$ & 0.172 & $13 \pm 9$ & 0.667 \\
\hline Grain bar & $13 / 19$ & $62 \pm 6$ & $-15 \pm 8$ & & $3 \pm 10$ & \\
\hline \multicolumn{7}{|c|}{ Fiber intake, g } \\
\hline Peanut & $15 / 15$ & $17 \pm 2$ & $3 \pm 2$ & 0.087 & $0.2 \pm 1.6$ & 0.672 \\
\hline Grain bar & $13 / 19$ & $17 \pm 2$ & $-1 \pm 2$ & & $1 \pm 2$ & \\
\hline
\end{tabular}

${ }^{1}$ Data represent mean \pm SE. P values for ANCOVA with baseline value as covariate. There were no significant differences between groups at baseline or during the trial. ${ }^{2}$ Three day diet records were kept prior to the start of the trial (baseline), at week 1 (the first 3 days of the trial), and at week $8 .{ }^{3}$ Reduced sample sizes reflect missing diet records.

nervous system action [41]. Although not assessed in the present report, others have shown that carbohydrates and nuts appear to have differing effects on GLP-1 release, a fact that may help explain the results reported herein. Stimulation of the sodium-glucose cotransporter-1 is believed to play a role in GLP-1 release [42] and both high-glycemic and low-glycemic carbohydrates effectively stimulate GLP-1 release, an effect which is sustained for over 3 hours [35,43]. Nut ingestion, however, displayed a more moderate effect on GLP-1 release, and blood concentrations fell to below baseline after 60 minutes [44]. Further studies examining the role of preloads in promoting postmeal satiety and incretin hormone release are needed to elucidate mechanisms.

In the 8-week trial, a single serving of peanuts $(170 \mathrm{kcal})$ or the control treatment, a grain bar $(140 \mathrm{kcal})$, were ingested in a structured manner, one hour prior to the evening meal. Theoretically, consuming a modest serving of peanuts as a preload to the evening meal would maximize their purported satiating effects and possibly contribute to weight loss over time [16,17]. However, consistent with the previous trials, daily consumption of nuts did not impact 24-h energy intakes or body weight. It may be that greater quantities of nuts $(>48 \mathrm{~g})$ are necessary to increase satiation [26,45]; but, given the caloric load of this quantity of nuts, measurable losses in body mass are not likely to be noted, at least over the short-term. Surprisingly, daily grain bar ingestion did reduce body weight significantly after 8 weeks. The favorable impact of grain bar ingestion on body weight was also noted at study weeks 2 and 6 as well as at the 4-week follow-up (Figure 3).
The success of grain bar ingestion for managing energy intake was realized early in the trial. Although the change from baseline for mean energy intakes in the first week of the trial did not differ significantly between groups, the change in energy intake was weakly related to change in body weight at week 2 for all participants $(r=0.339, p=0.077)$. The decision to preload the evening meal in this trial may have revealed an unforeseen benefit. The significant reductions in mid-day mealtime energy intakes reported by Farajian et al. [37] for a fiberrich carbohydrate preload were not sustained after a $24 \mathrm{~h}$ period indicating that energy compensation occurred later that day. In the present trial, by preloading the final meal of the day, the mealtime energy reductions related to the grain bar preload appeared not to have been compensated for prior to bedtime. Moreover, daily grain bar ingestion lowered hemoglobin A1c significantly after 8 weeks compared to peanut ingestion. The favorable impact for regular grain bar ingestion on diabetic biomarkers is novel and deserves further investigation.

Limitations of this study include the use of diet records to estimate energy intakes and compliance to the feeding study protocol. Although compliance did not differ significantly between groups, compliance may have impacted study outcomes. However, the significance for weight loss between groups was retained when only the compliant participants were examined $(p=0.047)$. Participants were overweight but healthy by self-report; hence, these results may not apply to normal weight populations or those with cardiovascular disease or diabetes. When considering the glucostatic theory as presented by Mayer 
[37], glycemic carbohydrates are not well utilized in the diabetic state; hence, a glycemic carbohydrate preload one hour prior to mealtime may not curb hunger in individuals with insulin resistance or diabetes. However, study participants were free-living allowing for natural eating behaviors and contributing to the external validity of the study. The lack of glucose and insulin data at 30 minutes following the ingestion of the preloads is another important limitation in this trial. Future trials should closely follow satiety and glycemic responses after preload ingestion and prior to meal ingestion. Trials of longer duration (6-12 months) are needed to better understand the role of glycemic carbohydrate preloads for weight management, and the measurement of the satiety peptides, e.g., GLP-1, will provide useful physiological information regarding mechanisms.

These data indicate that a low-energy, glycemic carbohydrate preload to the evening meal reduced 24-h energy intakes in healthy, overweight adults, resulting in significant reductions in body weight. A peanut preload (28 g) did not impact 24-h intakes or body weight in this population. Simple, inexpensive, and practical weight loss strategies, easily adopted by children and adults across diverse populations groups, are needed to help combat obesity. Although glycemic carbohydrates are a controversial topic in the recent literature, low-energy, glycemic carbohydrates may have a useful role as a preload. More research is needed to investigate the usefulness of preloads on eating behaviors and weight loss.

\section{Abbreviations}

AUC: Area-under-the-curve; BMI: Body mass index; GLP-1: Glucagon-like peptide 1; LOCF: Last observation carried forward.

\section{Competing interests}

CSJ has received reimbursements from the Peanut Institute, Albany GA, and funding from the National Peanut Board, Atlanta GA, and the Almond Board of California, Modesto CA.

\section{Authors' contributions}

CSJ designed the research, analyzed and interpreted data, and wrote the manuscript; CMT and KRF conducted the research, compiled and interpreted the data, and edited the manuscript. All authors read and approved the final manuscript.

Supported by a grant from the National Peanut Board, Atlanta GA.

\section{Acknowledgments}

This work was supported by a grant from the National Peanut Board, Atlanta GA. The funding sponsor participated in protocol design and data discussions. We thank Ginger Hook, RN for excellent phlebotomy and technical assistance, and Brooke Bjorge-Schohl, MS, RD for diet analysis.

Received: 11 October 2012 Accepted: 15 March 2013

Published: 27 March 2013

\section{References}

1. Center for Disease Control: Behavioral risk factor surveillance system. http:// apps.nccd.cdc.gov/brfss/list.asp?cat=OB\&yr=2010\&qkey=4409\&state=All.

2. Center for Disease Control: FastStats. http://www.cdc.gov/nchs/fastats/ overwt.htm.
3. Fraser GE, Sabaté J, Beeson WL, Strahan TM: A possible protective effect of nut consumption on risk of coronary heart disease. The adventist health study. Arch Intern Med 1992, 152:1416-1424.

4. Sabaté J: Nut consumption and body weight. Am J Clin Nutr 2003, 78(3 Suppl):647S-650S.

5. Mattes RD: The energetics of nut consumption. Asia Pac J Clin Nutr 2008, 17(Suppl 1):337-339.

6. Gilbert JA, Bendsen NT, Tremblay A, Astrup A: Effect of proteins from different sources on body composition. Nutr Metab Cardiovasc Dis 2011, 21(Suppl 2):B16-B31.

7. Coates AM, Howe PR: Edible nuts and metabolic health. Curr Opin Lipidol 2007, 18:25-30.

8. Mollard $\mathrm{RC}$, Wong $\mathrm{CL}$, Luhovyy $\mathrm{BL}$, Anderson GH: First and second meal effects of pulses on blood glucose, appetite, and food intake at a later meal. Appl Physiol Nutr Metab 2011, 36:634-642.

9. Warren JM, Henry CJ, Simonite V: Low glycemic index breakfasts and reduced food intake in preadolescent children. Pediatrics 2003, 112:e414

10. Johnston CS, Buller AJ: Vinegar and peanut products as complementary foods to reduce postprandial glycemia. J Am Diet Assoc 2005, 105:1939-1942.

11. Josse AR, Kendall CW, Augustin LS, Ellis PR, Jenkins DJ: Almonds and postprandial glycemia-a dose-response study. Metabolism 2007, 56:400-404

12. Jenkins DJ, Kendall CW, Josse AR, Salvatore S, Brighenti F, Augustin LS, Ellis $P R$, Vidgen E, Rao AV: Almonds decrease postprandial glycemia, insulinemia, and oxidative damage in healthy individuals. J Nutr 2006, 136:2987-2992.

13. Fraser GE, Bennett HW, Jaceldo KB, Sabaté J: Effect on body weight of a free 76 Kilojoule (320 calorie) daily supplement of almonds for six months. J Am Coll Nutr 2002, 21:275-283.

14. Hollis J, Mattes R: Effect of chronic consumption of almonds on body weight in healthy humans. Br J Nutr 2007, 98:651-656.

15. Zaveri S, Drummond S: The effect of including a conventional snack (cereal bar) and a nonconventional snack (almonds) on hunger, eating frequency, dietary intake and body weight. J Hum Nutr Diet 2009, 22:461-468.

16. Bertenshaw EJ, Lluch A, Yeomans MR: Dose-dependent effects of beverage protein content upon short-term intake. Appetite 2009, 52:580-587.

17. Anderson GH, Tecimer SN, Shah D, Zafar TA: Protein source, quantity, and time of consumption determine the effect of proteins on short-term food intake in young men. J Nutr 2004, 134:3011-3015.

18. Kirkmeyer SV, Mattes RD: Effects of food attributes on hunger and food intake. Int J Obes Relat Metab Disord 2000, 24:1167-1175.

19. Cardello AV, Schutz HG, Lesher LL, Merrill E: Development and testing of a labeled magnitude scale of perceived satiety. Appetite 2005, 44:1-13.

20. Johnston CS, Steplewska I, Long CA, Harris LN, Ryals RH: Examination of the antiglycemic properties of vinegar in healthy adults. Ann Nutr Metab 2010, 56:74-79.

21. Mattes RD, Kris-Etherton PM, Foster GD: Impact of peanuts and tree nuts on body weight and healthy weight loss in adults. J Nutr 2008, 138:1741S-1745S.

22. Sabaté J, Ang Y: Nuts and health outcomes: new epidemiologic evidence. Am J Clin Nutr 2009, 89:1643S-1648S.

23. Martínez-González MA, Bes-Rastrollo M: Nut consumption, weight gain and obesity: epidemiological evidence. Nutr Metab Cardiovasc Dis 2011, 21(Suppl 1):S40-S45.

24. Rajaram S, Sabaté J: Nuts, body weight and insulin resistance. Br J Nutr 2006, 96(Suppl 2):S79-S86.

25. Mattes RD, Dreher ML: Nuts and healthy body weight maintenance mechanisms. Asia Pac J Clin Nutr 2010, 19:137-141.

26. Claesson AL, Holm G, Ernersson A, Lindström T, Nystrom FH: Two weeks of overfeeding with candy, but not peanuts, increases insulin levels and body weight. Scand J Clin Lab Invest 2009, 69:598-605.

27. Casas-Agustench P, Lopez-Uriarte P, Bullo M, Ros E, Cabre-Vila JJ, Salas-Salvado $\mathrm{J}$ : Effects of one serving of mixed nuts on serum lipids, insulin resistance and inflammatory markers in patients with the metabolic syndrome. Nutr Metab Cardiovasc Dis 2011, 21:126-135.

28. Li Z, Song R, Nguyen C, Zerlin A, Karp H, Naowamondhol K, Thames G, Gao K, Li $\mathrm{L}$, Tseng $\mathrm{CH}$, Henning SM, Heber D: Pistachio nuts reduce triglycerides and body weight by comparison to refined carbohydrate snack in obese subjects on a 12-week weight loss program. J Am Coll Nutr 2010, 29:198-203.

29. Tey SL, Brown R, Gray A, Chisholm A, Delahunty C: Nuts improve diet quality compared to other energy-dense snacks while maintaining body weight. J Nutr Metab 2011, 2011:357350. 
30. Bowen J, Noakes M, Trenerry C, Clifton PM: Energy intake, ghrelin, and cholecystokinin after different carbohydrate and protein preloads in overweight men. J Clin Endocrinol Metab 2006, 91:1477-1483.

31. Krog-Mikkelsen I, Sloth B, Dimitrov D, Tetens I, Bjorck I, Flint A, Holst JJ, Astrup A, Elmstahl H, Raben A: A low glycemic index diet does not affect postprandial energy metabolism but decreases postprandial insulinemia and increases fullness ratings in healthy women. J Nutr 2011, 141:1679-1684.

32. Henry CJ, Lightowler HJ, Strik CM: Effects of long-term intervention with low- and high-glycaemic-index breakfasts on food intake in children aged 8-11 years. Br J Nutr 2007, 98:636-640.

33. Anderson GH, Woodend D: Effect of glycemic carbohydrates on shortterm satiety and food intake. Nutr Rev 2003, 61:S17-S26.

34. Wu T, Zhao BR, Bound MJ, Checklin HL, Bellon M, Little TJ, Young RL, Jones KL, Horowitz M, Rayner CK: Effects of different sweet preloads on incretin hormone secretion, gastric emptying, and postprandial glycemia in healthy humans. Am J Clin Nutr 2012, 95:78-83.

35. Anderson GH, Catherine NLA, Woodend DM, Wolever TMS: Inverse association between the effect of carbohydrates on blood glucose and subsequent short-term food intake in young men. Am J Clin Nutr 2002. 76:1023-1030

36. Farajian $\mathrm{P}$, Katsagani $\mathrm{M}$, Zampelas A: Short-term effects of a snack including dried prunes on energy intake and satiety in normal-weight individuals. Eating Behav 2010, 11:201-203.

37. Mayer J: The glucostatic theory of regulation of food intake and the problem of obesity. Bull New Engl Med Cent 1952, 14:43-49.

38. Akhavan T, Luhovyy BL, Brown PH, Cho CE, Anderson GH: Effect of premeal consumption of whey protein and its hydrolysate on food intake and postmeal glycemia and insulin responses in young adults. Am J Clin Nutr 2010, 91:966-975.

39. Nilsson M, Stenberg M, Frid AH, Holst JJ, Björck IM: Glycemia and insulinemia in healthy subjects after lactose-equivalent meals of milk and other food proteins: the role of plasma amino acids and incretins. Am J Clin Nutr 2004, 80:1246-1253.

40. van Loon $L$, Saris WH, Verhagen H, Wagenmakers AJ: Plasma insulin responses after ingestion of different amino acid or protein mixtures with carbohydrate. Am J Clin Nutr 2000, 72:96-105.

41. Punjabi M, Arnold M, Geary N, Langhans W, Pacheco-López G: Peripheral glucagon-like peptide-1 (GLP-1) and satiation. Physiol Behav 2011, 105:71-76.

42. Moriya R, Shirakura T, Ito J, Mashido S, Seo T: Activation of sodium-glucose cotransporter 1 ameliorates hyperglycemia by mediating incretin secretion in mice. Am J Physiol Endocrinol Metab 2009, 297:E1358-E1365.

43. Milton JE, Sananthanan CS, Patterson M, Ghatei MA, Bloom SR, Frost GS: Glucagon-like peptide-1 (7-36) amide response to low versus high glycaemic index preloads in overweight subjects with and without type II diabetes mellitus. Eur J Clin Nutr 2007, 61:1364-1372.

44. Cassady BA, Hollis JH, Fulford AD, Considine RV, Mattes RD: Mastication of almonds: effects of lipid bioaccessibility, appetite, and hormone response. Am J Clin Nutr 2009, 89:794-800.

45. Brennan AM, Sweeney LL, Liu X, Mantzoros CS: Walnut consumption increases satiation but has no effect on insulin resistance or the metabolic profile over a 4-day period. Obesity (Silver Spring) 2010, 18:1176-1182.

doi:10.1186/1475-2891-12-35

Cite this article as: Johnston et al:: The effect of peanut and grain bar preloads on postmeal satiety, glycemia, and weight loss in healthy individuals: an acute and a chronic randomized intervention trial. Nutrition Journal 2013 12:35.

\section{Submit your next manuscript to BioMed Central and take full advantage of:}

- Convenient online submission

- Thorough peer review

- No space constraints or color figure charges

- Immediate publication on acceptance

- Inclusion in PubMed, CAS, Scopus and Google Scholar

- Research which is freely available for redistribution

Submit your manuscript at www.biomedcentral.com/submit
Ciomed Central 